\title{
Significance of apoptosis in the process of tumorigenesis in colorectal mucosa and adenomas in FAP patients
}

\author{
Hildegard Wei $\aleph^{\mathrm{a}}$, Karl-Heinz Jacobasch ${ }^{\mathrm{a}}$, Wolfgang Haensch ${ }^{\mathrm{a}}$, Brigitte Streller ${ }^{\mathrm{b}}$ and \\ Brigitte Hieke ${ }^{\mathrm{a}}$ \\ ${ }^{a}$ Robert-Rössle-Klinik des Universitätsklinikums Rudolf Virchow, Lindenbergerweg 80, \\ 13125 Berlin, Germany \\ ${ }^{\mathrm{b}}$ Gemeinsames Krebsregister, Brodauerstr. 16/22, 12621 Berlin, Germany
}

Received 26 June 1996

Revised 10 February 1997

Accepted 19 March 1997

\begin{abstract}
The relation between proliferation and apoptosis was studied in colorectal mucosal biopsies $(N=41)$, tubular adenomas (TA) $(N=104)$ and tubulovillous adenomas (TVA) $(N=34)$ from 37 FAP patients. Proliferative activity was determined by cell cycle distribution analysis. In addition, transcriptional capacity was determined by chromatin in situ testing. For both, DNA flow cytometry was used. Cycling cells were identified by immunohistochemical staining with monoclonal antibody Ki67. The existence of subdiploid apoptotic cells was derived from DNA and/or DNA/protein patterns. In a follow-up group, the mucosa is characterised by a balance between proliferation (S \% + G2M \%= 19) and apoptotic cells $(\%=17)$. The percentage of Ki67 positive cells $(16 \%)$ corresponds to the percentages mentioned above. In TA, the amount of apoptotic cells remains unaltered, in TVA it decreases to $8 \%$. At the same time, the percentage of Ki67 positive cells increases significantly in both TA and TVA $(39 \%, 42 \%)$. With patients who underwent surgery due to clinical signs without histological evidence for malignancy, apoptotic cells in TA continue to decrease significantly ( $9 \%$ ), without any changes in cycling cells. Only in the carcinoma-bearing bowel, cycling cells increase to $52 \%$. Here, the percentage of apoptotic cells in TVA reaches the lowest level (5\%). A connection between proliferation and apoptosis was observed in mucosa and TVA. The process of tumorigenesis is characterised by a stepwise increase in resistance to apoptosis followed by an increase in cycling cells.
\end{abstract}

Keywords: FAP, flow cytometry, proliferation, apoptosis, colorectal mucosa, adenomas, Ki67 score

\section{Introduction}

Familial adenomatous polyposis (FAP) is an autosomal dominant disorder due to a germline alteration of the adenomatous polyposis coli gene on the long arm of chromosome 5 [5,22,30]. FAP is characterised by the formation of hundreds of colorectal adenomas in young adults. This leads to colorectal cancer by the fifth decade of life if no prophylactic colectomy is performed [7]. The goal of this study was to investigate cell kinetics in colorectal mucosa and adenomas in FAP patients. 
The majority of patients was recruited from the FAP follow-up group examined at the Robert-RössleKlinik.

When studying proliferation conditions, the focus lay on monitoring the loss of balance between cell proliferation and programmed cell death (apoptosis) during progressing malignisation. The importance of inhibiting apoptosis during the development of colorectal cancer has recently also been demonstrated by other researchers $[3,31,34]$. A deeper knowledge of the change from balance to imbalance between cell proliferation, differentiation and programmed cell death may help to determine the optimum time for surgical interventions and for application of drugs inducing apoptosis $[3,31,34,45]$.

Cell proliferative activity and capability were derived from cell cycle stage analysis and chromatin in situ testing applying flow cytometry $[24,32,39,44]$. Additional growth fraction was derived from immunohistochemically determined Ki67 expression [13]. These methods do not provide any information about the length of cell cycle phases. They should only be considered as part of the discussion. Apoptotic cells were detected by flow cytometry [18]. Correlations to histopathological findings and clinical factors were established.

\section{Patients and methods}

\subsection{Study population}

In total, 37 FAP patients from 22 families were examined. They were included in a surveillance programme at Robert-Rössle-Klinik (RRK). In addition, two patients from two families who underwent surgery at RRK were examined.

The follow-up group consisted of 25 FAP patients who were free of malignancy and 10 FAP patients who had evidence of malignancy during the follow-up period. During the research described here, all were free of carcinoma.

The surgically treated group consisted of eight patients. With four of them, the need for surgery was determined from the size, distribution and number of polyps. Malignancy was not evident in the resection materials. With two other patients, malignant histological findings led to surgical treatment. Two FAP patients entered RRK for surgery. The resection material revealed carcinomas in all four cases.

\subsection{Tissue samples and analysis methods}

During routine endoscopical examination, biopsies were taken from colorectal adenomas randomly selected, and from surrounding flat mucosa. The biopsies were taken in such a way that specimens from the same location were divided for histological, immunohistochemical and flow cytometrical investigations. Using flow cytometry, samples from 40 tubular and 17 tubulovillous adenomas and 41 mucosal biopsies were measured. Immunohistochemical determination of Ki67 positive cells was performed in 30 samples.

From resected bowels, between 10 and 20 adenomas per case were taken and divided for the three investigation methods. These adenomas did not show any macroscopical signs of malignancy. From the carcinoma-free bowel, samples from 29 tubular adenomas and two tubulovillous adenomas were available for flow cytometry. From carcinoma-bearing bowel, 35 samples from tubular and 18 from tubulovillous adenomas were available. Ki67 positive cells were counted in 24 samples from the carcinoma-free and in 52 samples from the carcinoma-bearing bowel. 
Histopathological analysis: The histological classification of colorectal adenomas followed the 'histological typing of intestinal tumors' of the WHO [29].

Ki67 immunohistochemistry: Cryostat sections were stained using a monoclonal mouse antibody designed as DAKO-PC, Code No. M722 at a dilution of 1:50. For detection, APAAP complexes were used according to Cordell et al. [8]. Negative controls consisted of sections incubated with PBS instead of anti-Ki67. Intrinsic positive controls were analysed in each series. The number of positive cells was counted by one observer. For counting, areas with a high frequency of stained cells [19] (about 200 cells) were selected. In the interest of reducing assessing subjectivity, any level of nuclear staining intensity was defined to be positive.

Flow cytometric analysis $(F C M)$ : Fresh tissue was stored at $-20^{\circ} \mathrm{C}$. After thawing, it was minced with scalpels. For DNA and DNA/protein analysis, the cells were fixed in ice-cold ethanol, washed in $0.9 \%$ saline and double-stained with DAPI/Sulforhodamine $101[9,18,25,37,43]$.

Univariate DNA distribution and bivariate DNA/protein distribution were measured with PAS II (Partec GmbH, Münster, Germany). Lymphocytes were measured for device alignment daily. DNA Index [16], cell cycle compartments and subdiploid apoptotic cells were quantified from the DNA pattern $[32,39]$. The apoptotic fraction was also determined by manual gating from the DNA/protein histogram [18].

Chromatin in situ tests applying heparin as a chromatin probe were carried out in non-fixed cells as described [44]. Briefly, unfixed cells were stained with Ethidium Bromide/Mithramycin [47] and the DNA patterns were recorded before $(t=0)$ and after $(t=1,4,7 \mathrm{~min})$ the addition of heparin $(7.5 \mathrm{U}$ per ml cell suspension) (Weddel Pharmaceutical Ltd., London). The percentages of cells sensitive and resistant to the increase in fluorescence intensity (IFI) induced by heparin were assessed after 7 and 10 min. Different accessibility of chromatin to fluorescence dyes reflects different chromatin types in cells. They are related to different transcriptional capacities: sensitive cells are assumed to be transcriptionally inactive, resistant cells to be active $[24,44]$. Not all cell parameters were calculable in each case.

\subsection{Statistical methods}

The Student's $t$-test was used for assessing the difference between means. The chi-square test was used for analysing frequency tables. The correlation coefficient was calculated in order to obtain a measure for linear dependence. It was tested against zero for the existence of some linear dependence. The statistics needed were calculated with the commercial computer program SPSS for Microsoft Windows Version 6.1 (SPSS Inc. 444n Michigan Avenue Chicago, IL 60611, USA).

\section{Results}

The main result is the recognition of a shift in balance between proliferation and apoptosis at the expense of apoptosis during stepwise malignisation in FAP. Steps investigated were colorectal mucosa, tubular and tubulovillous adenomas from patients without and with a carcinoma history, and adenomas from resection material derived from a carcinoma-free and a carcinoma-bearing bowel (Fig. 1). DNA ploidy, a significant parameter in the characterisation of precancer and cancer, does not reveal any differences (the result is not shown here, however). For the cell kinetic examination represented here, only the DNA diploid cases were used. 


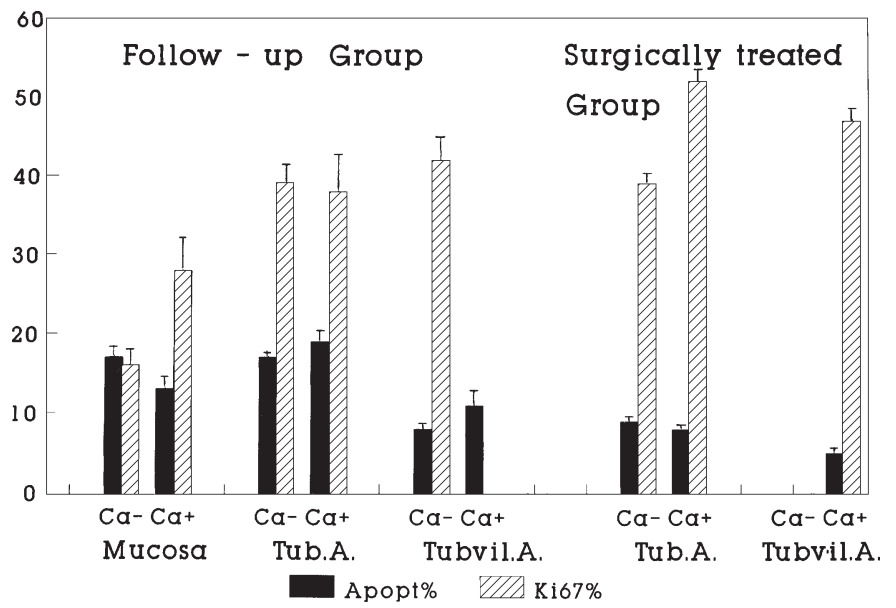

Fig. 1. Percentages of subdiploid apoptotic and Ki67 positive cells in colorectal mucosa and adenomas (A) $(M \pm m)$.

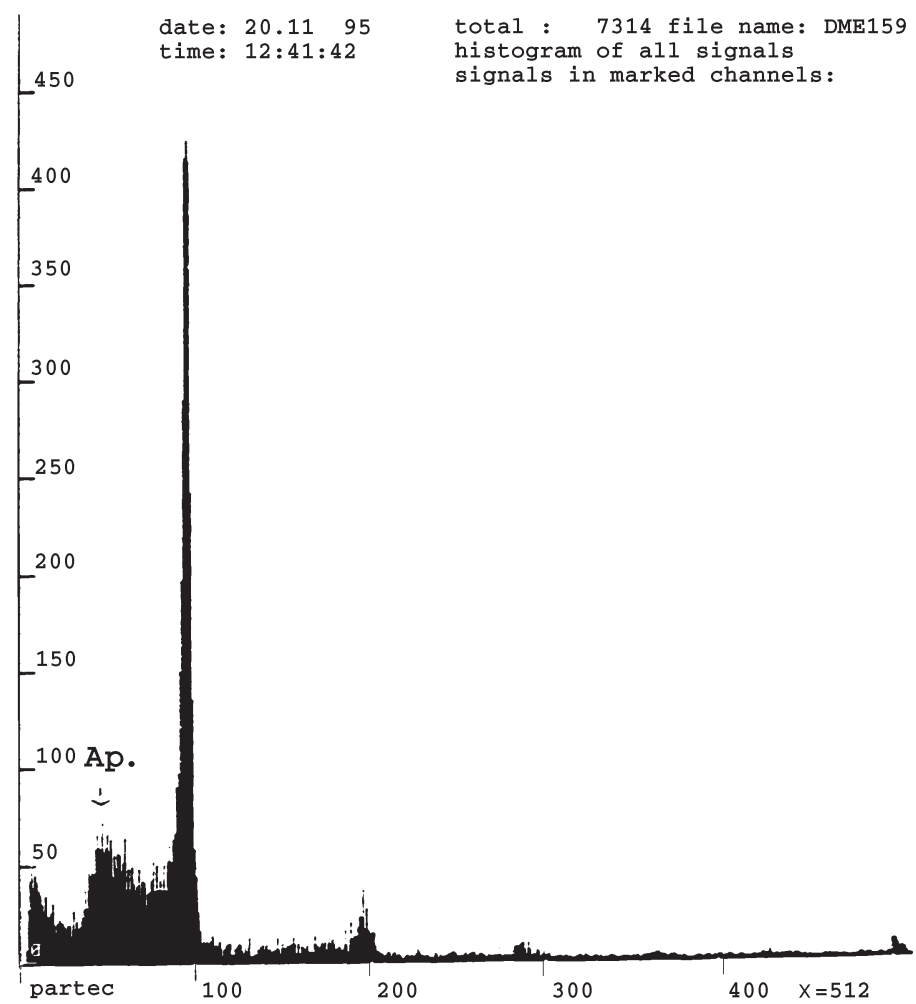

Fig. 2. Univariate DNA distribution of a colorectal mucosal biopsy. Subdiploid apoptotic cells are indicated.

\subsection{Follow-up group}

Examples for histograms of colorectal mucosal cells exhibiting apoptotic cells are given in Figs 2 and 3. Apoptotic cells are detectable in univariate DNA patterns and in bivariate DNA/protein patterns due to their decreased DNA and increased protein contents compared to cells in G1/0 phase [9]. 


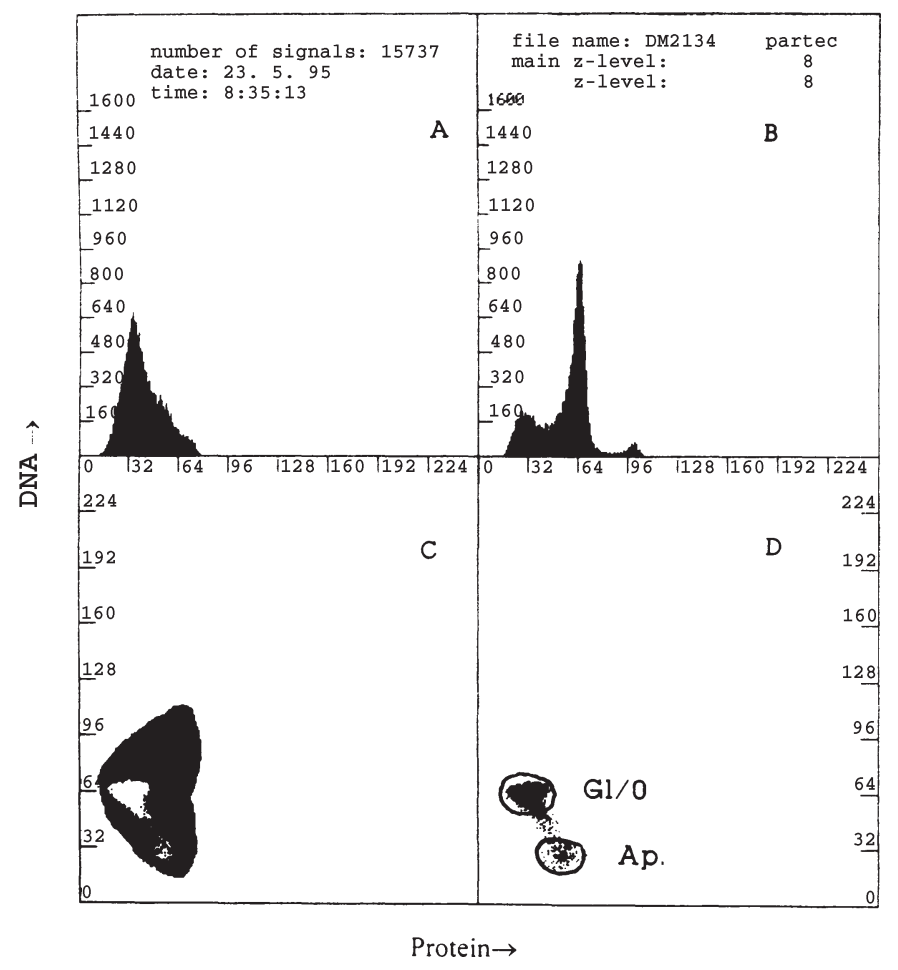

Fig. 3. Bivariate DNA/protein content distribution of a DNA diploid mucosal biopsy. Apoptotic cells (Ap) are indicated. (A) protein histogram: cellular protein content ( $x$-axis) is plotted vs. cell number ( $y$-axis). (B) DNA histogram: cellular DNA content ( $x$-axis) is plotted vs. cell number ( $y$-axis). (C) DNA/protein scatter diagram: cellular protein content ( $x$-axis) is plotted vs. cellular DNA content ( $y$-axis). The region for gating of cells is indicated. (D) equal to (C) without gated region. Apoptotic cells are characterised by diminished DNA content and slightly increased protein content compared to G1/0 cells.

Table 1

Cell cycle distribution, subdiploid apoptotic fraction and Ki67 positive cells in DNA diploid cases of colorectal mucosal biopsies from the FAP patients. Follow-up group without colorectal carcinoma $\left(\mathrm{Ca}^{-}\right)$or with colorectal carcinoma $\left(\mathrm{Ca}^{+}\right)$during the follow-up period $(M \pm m ; N)$

\begin{tabular}{lcccl}
\hline $\mathrm{Ca}^{ \pm}$ & $\mathrm{S} \%$ & G2M $\%$ & Apopt. $\%$ & Ki67 \% \\
\hline $\mathrm{Ca}^{-}$ & $8 \pm 0.7$ & $11 \pm 1.0$ & $17 \pm 2.5$ & $16 \pm 3.7$ \\
& $N=21$ & $N=21$ & $N=17$ & $N=6$ \\
$\mathrm{Ca}^{+}$ & $6 \pm 0.6$ & $9 \pm 0.6$ & $13 \pm 2.6$ & $28 \pm 7.3$ \\
& $N=20$ & $N=20$ & $N=12$ & $N=5$ \\
\hline
\end{tabular}

Statist. significances: $\mathrm{Ca}^{-}$vs. $\mathrm{Ca}^{+}: \mathrm{S} \%(p<0.002)$.

Follow-up group $\left(\mathrm{Ca}^{-}\right)$: Colorectal mucosa vs. tubular adenoma: Ki67 \% $(p<0.002)$, colorectal mucosa vs. tubulovillous adenoma: Apopt. \% $(p<0.01)$; Ki67 \% $(p<0.01)$.

Patients without a history of malignancy tend to show higher percentages of subdiploid apoptotic cells and lower percentages of Ki67 positive cells, when compared to patients with a history of malignancy (apoptotic cells \%: $17 \pm 2.5$ vs. $13 \pm 2.6$; Ki67 \%: $16 \pm 3.7$ vs. $28 \pm 7.3$, n.s.) (Fig. 1 , Table 1). In cases without cancer history, the sum of cells in $S$ and G2M phases, the percentage of 

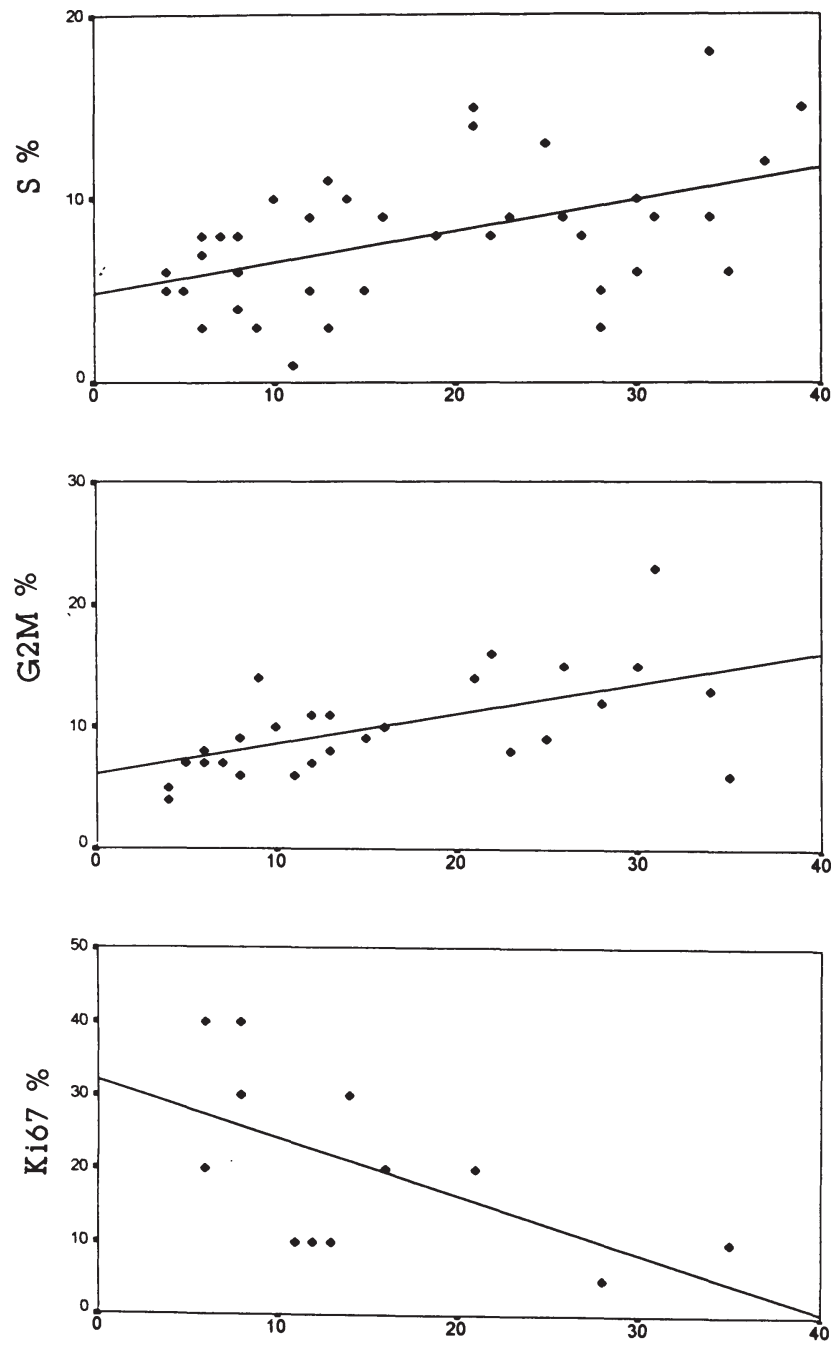

Apoptosis \%

Fig. 4. Correlation between apoptosis and proliferation in colorectal mucosa. Top: Apoptotic cells \% vs. S \% ( $\rho=0.369$, $p<0.05, N=29)$. Middle: Apoptotic cells $\%$ vs. G2M \% $(\rho=0.592, p<0.001, N=29)$. Bottom: Apoptotic cells $\%$ vs. Ki67 positive cells $\%(\rho=-0.612, p=0.06, N=10)$.

apoptotic cells and the percentage of Ki67 positive cells are approximately the same. In cases with cancer history, Ki67 positive cells are dominant.

Independent of cancer history, Ki67 positive cells are confined to the lower parts of the crypts, as also seen by others [4,19]. Only in one case in this group, were Ki67 positive cells evident in the middle part of the crypts.

For mucosal cells independent of carcinoma history, positive relations exist between subdiploid apoptotic fraction and $\mathrm{S}$ phase fraction $(\rho=0.369, p=0.05, N=29)$ as well as between apoptotic fraction and $\mathrm{G} 2 \mathrm{M}$ phase fraction $(\rho=0.592, p=0.001, N=29)$. A reverse relation is suggested between subdiploid apoptotic fraction and Ki67 positive cells $(\rho=-0.612, p=0.06, N=10)$ (Fig. 4). A relation between the proliferative parameters $\mathrm{S}$ and G2M phase fraction is evident $(\rho=$ $0.312, p<0.05, N=41)$. 
Table 2

Cell cycle distribution, subdiploid apoptotic fraction and Ki67 positive cells in DNA diploid cases of colorectal adenomas from FAP patients. Follow-up group without colorectal carcinoma $\left(\mathrm{Ca}^{-}\right)$or with colorectal carcinoma $\left(\mathrm{Ca}^{+}\right)$during the follow-up period $(M \pm m ; N)$

\begin{tabular}{llclll}
\hline $\mathrm{Ca}^{ \pm}$ & Histol. finding & $\mathrm{S} \%$ & G2M \% & Apopt. \% & Ki67 \% \\
\hline $\mathrm{Ca}^{-}$ & Tub. adenoma & $8 \pm 0.9$ & $10 \pm 1.0$ & $17 \pm 1.5$ & $39 \pm 4.6$ \\
& & $N=29$ & $N=30$ & $N=17$ & $N=9$ \\
& Tubvill. adenoma & $9 \pm 0.9$ & $10 \pm 1.0$ & $8 \pm 1.0$ & $42 \pm 5.7$ \\
& & $N=9$ & $N=6$ & $N=6$ \\
$\mathrm{Ca}^{+}$ & Tub. adenoma & $8 \pm 1.6$ & $10 \pm 0.8$ & $19 \pm 2.4$ & $38 \pm 8.6$ \\
& & $N=10$ & $N=10$ & $N=8$ & $N=4$ \\
& Tubvill. adenoma & $7 \pm 1.2$ & $12 \pm 1.3$ & $11 \pm 3.1$ & \\
& & $N=7$ & $N=7$ & $N=6$ & \\
\hline
\end{tabular}

Statist. significance: Follow-up group $\left(\mathrm{Ca}^{-}\right)$: Tubular adenomas vs. tubulovillous adenomas; Apopt. \% $(p<0.001)$.

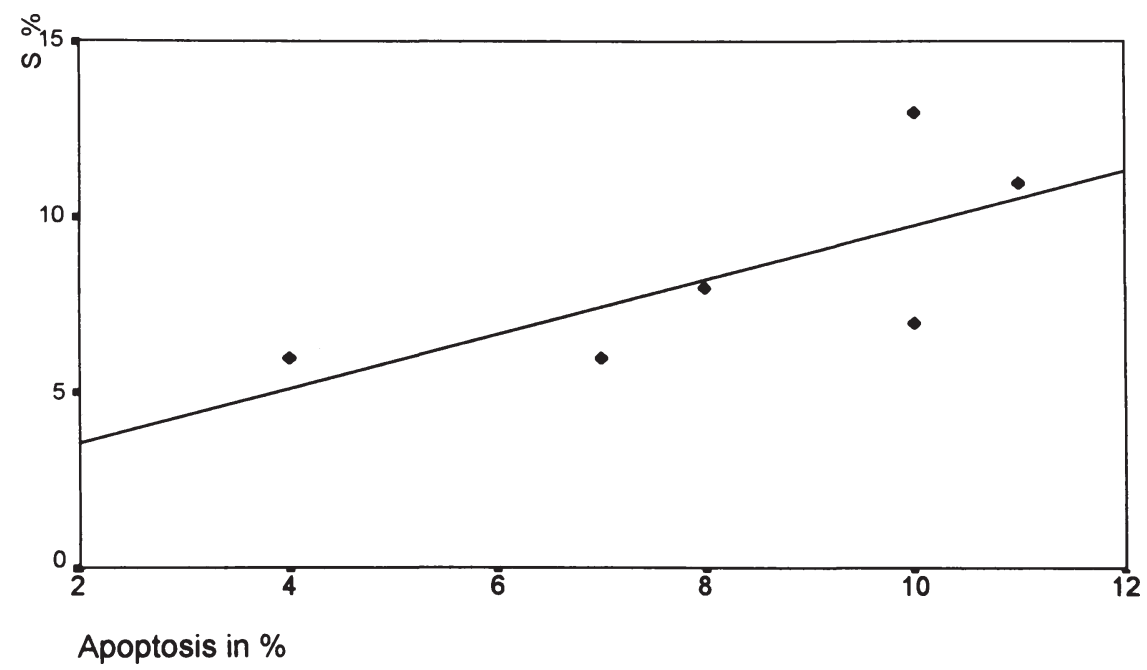

Fig. 5. Correlation between apoptosis and proliferation in tubulovillous adenomas, follow-up group, patients with carcinoma history: Apoptotic cells \% vs. S \% $(\rho=0.875, p<0.02, N=6)$.

In adenomas, there are no obvious differences which may be due to whether a history of malignancy exists or not. The apoptotic fraction does not change in tubular adenomas compared to mucosa. In tubulovillous adenomas, it decreases considerably below the level of mucosa or tubular adenomas ( $8 \pm 1.0$ vs. $17 \pm 2.5 ; 17 \pm 1.5, p<0.01)$. The percentage of Ki67 positive cells increases in tubular and tubulovillous adenomas compared to mucosa $(39 \pm 4.6 ; 42 \pm 5.7$ vs. $16 \pm 3.7, p<0.01)$. Both the proliferative compartment and Ki67 positive cells exceed the apoptotic fraction (Fig. 1, Table 2).

Ki67 positive cells are predominantly present in the superficial layer with a high frequency in dysplastic areas. This corresponds to known facts $[4,19]$. In cases without cancer history, the proliferative parameters $\mathrm{S}$ and $\mathrm{G} 2 \mathrm{M}$ phase fraction are related in tubular adenomas $(\rho=0.457, p=0.02, N=25)$. A positive relation between the apoptotic fraction and the $\mathrm{S}$ phase fraction is evident in tubulovillous adenomas ( $\rho=0.875, p=0.02, N=6)$ (Fig. 5). The same applies to all adenomas of the follow-up group $(\rho=0.354, p=0.034, N=36)$. 


\subsection{Surgical treatment group}

In the bowel free of cancer, tubular adenomas are characterised by a distinct decrease in apoptotic cells compared to those in the follow-up group $(9 \pm 0.8$ vs. $17 \pm 1.5 ; 19 \pm 2.4 ; p<0.01)$. The proliferative compartment and the percentage of Ki67 positive cells remain unchanged (Fig. 1, Table 3).

The Ki67 positive cells are located in the superficial layer in the same way as in the follow-up group.

Chromatin in situ test (Fig. 6) identified cells resistant to the increase in fluorescence intensity induced by heparin in 5 out of 21 cases. These transcriptionally active cells account for $13 \pm 1.9 \%$ and $12.2 \pm 2.6 \%$ at the 7 th and 10th minute after starting the heparin reaction.

The proliferative parameters $\mathrm{S}$ phase and G2M phase fraction are related to each other $(\rho=$ 0.424, $p=0.034, N=25$ ). Tubulovillous adenomas cannot be considered, as there were only two cases available.

In the carcinoma-bearing bowel, tubular adenomas reveal a reduced percentage of apoptotic cells $(8 \pm 0.4)$. In addition, they are characterised by a significant increase in Ki67 positive cells $(52 \pm 2.5$ vs. $39 \pm 2.7, p<0.05)$. Chromatin in situ test revealed resistant cells in a significantly higher frequency ( 13 out of 22 cases, $p<0.03$ ). The percentage of resistant cells is considerably but not significantly higher. It accounts for $18.7 \pm 3.7$ and $20.5 \pm 5.4 \%$ at the 7 th and 10th min. The proliferative parameters $\mathrm{G} 2 \mathrm{M}$ phase fraction $(\rho=0.61, p<0.00, N=35)$, Ki67 positive cells $(\rho=0.36, p<0.033, N=35)$ and percentage of resistant cells $(\rho=0.569, p=0.067, N=11)$ are related, or tend to be related, to the $\mathrm{S}$ phase fraction. A relation between apoptosis and proliferative activity could not be established.

Tubulovillous adenomas reach the lowest level of apoptotic cells $(5 \pm 0.7)$. The percentages of cells in the S and G2M phases also decrease significantly (Table 3). Cycling cells remain constant (Fig. 1).

Chromatin in situ test identifies resistant cells in 11 out of 24 cases. The number of resistant cells accounts for $17.2 \pm 2.9 \%, 7 \mathrm{~min}$. There are no differences to tubular adenomas. The apoptotic fraction seems to be positively related to Ki67 positive cells ( $\rho=0.59, p=0.07, N=10$ ) (Fig. 7).

In both tubular and tubulovillous adenomas, Ki67 positive cells are distributed over the superficial epithelial cell layer. They are also found in the deeper parts, but in disseminated clusters.

Table 3

Cell cycle distribution, subdiploid apoptotic fraction and Ki67 positive cells in DNA diploid cases of colorectal adenomas from surgical specimens from FAP patients with carcinoma-free $\left(\mathrm{Ca}^{-}\right)$or carcinoma-bearing bowel $\left(\mathrm{Ca}^{+}\right)(M \pm m ; N)$

\begin{tabular}{llcccc}
\hline $\mathrm{Ca}^{ \pm}$ & Histol. finding & $\mathrm{S} \%$ & G2M \% & Apopt. \% & Ki67 \% \\
\hline $\mathrm{Ca}^{-}$ & Tub. adenoma & $7 \pm 0.5$ & $9 \pm 0.7$ & $9 \pm 0.8$ & $39 \pm 2.7$ \\
& & $N=29$ & $N=29$ & $N=23$ & $N=24$ \\
& Tubvill. adenoma & & & \\
$\mathrm{Ca}^{+}$ & Tub. adenoma & $7 \pm 0.6$ & $8 \pm 0.4$ & $8 \pm 0.9$ & $52 \pm 2.5$ \\
& & $N=35$ & $N=35$ & $N=31$ & $N=34$ \\
& Tubvill. adenoma & $5 \pm 0.5$ & $7 \pm 0.3$ & $5 \pm 0.7$ & $47 \pm 2.4$ \\
& $N=18$ & $N=18$ & $N=9$ & $N=18$ \\
\hline
\end{tabular}

Statist. significances: Carcinoma-free bowel vs. carcinoma-bearing bowel: Tubular adenoma: Ki67 \% $(p<0.05)$.

Carcinoma-bearing bowel: Tubular adenoma vs. tubulovillous adenoma: Apopt. $\%(p<0.02)$; $\mathrm{S} \%, \mathrm{G} 2 \mathrm{M} \%(p<0.05)$

Carcinoma-free bowel, carcinoma-bearing bowel vs. follow-up group $\mathrm{Ca}^{-}, \mathrm{Ca}^{+}$: Apopt. \% $(p<0.001)$. 


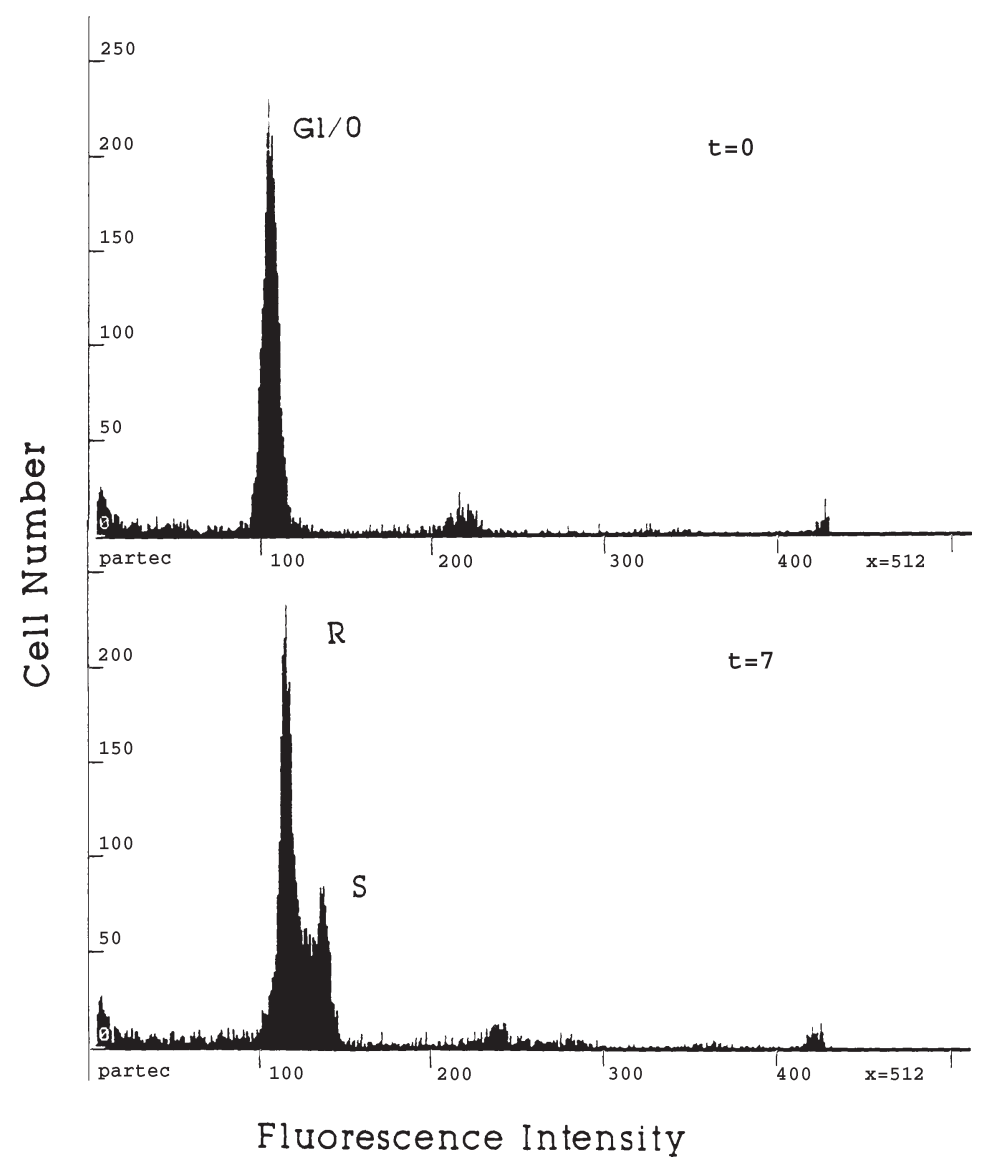

Fig. 6. Identification of cells sensitive ( $S$ ) and resistant (R) to increase in fluorescence intensity (IFI) induced by heparin, illustrated by two consecutively recorded DNA patterns in a colorectal adenoma. The percentages of resistant and sensitive cells amount to $60 \%$ and $40 \%$. Sensitivity is related to condensed chromatin of transcriptionally inactive cells, resistance to dispersed chromatin of transcriptionally active cells.

The frequency distribution of the histological types tubular and tubulovillous differs significantly between carcinoma-free ( 25 tubular/2 tubulovillous adenomas) and carcinoma-bearing bowel (35 tubular/17 tubulovillous adenomas) $(p<0.05)$.

\section{Discussion}

Recently, inhibited apoptosis due to deregulated and enhanced bcl-2 expression in colorectal mucosa, tubular and tubulovillous adenomas in FAP patient has been reported [3]. Especially in the early phases of the adenoma-carcinoma sequence, bcl-2 oncoprotein participates in colorectal tumorigenesis [6], accumulating long-lived cells predisposed to malignancy. Besides bcl-2, the genes, c-myc and p53 are involved in regulating the susceptibility and resistance to apoptosis in the colon $[12,17,21,27,46]$.

The relation between susceptibility to apoptosis and proliferative activity is of clinical significance. It was investigated in different cell systems, but the results are contradictory: Close linkage [46], enhanced proliferation together with diminished cell death [26], low expression of bcl-2 in Ki67 


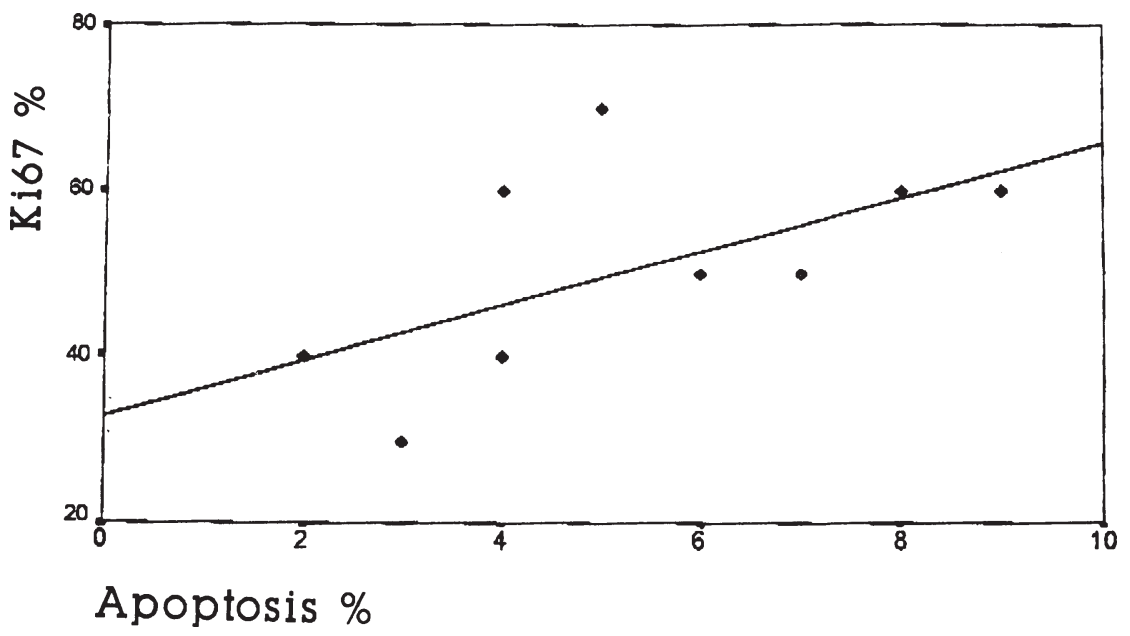

Fig. 7. Correlation between apoptotic cells $\%$ and Ki67 positive cells $\%$ in tubulovillous adenomas gained from the carcinoma-bearing bowel $(\rho=0.59, p=0.07, N=10)$.

positive cells but also co-expression of bcl-2 and Ki67 at high levels [33], high S phase fractions associated with high apoptosis and vice versa [35], high Ki67 index associated with high apoptosis [2] and high labeling indices related to high apoptosis [20] have been reported.

In the present study, susceptibility to apoptosis was related to proliferation in mucosa and in tubulovillous adenomas. This relation, however, occurred in somewhat different ways and to a different extent. No correlation was evident in tubular adenomas. Different genetic alterations may be due to different regulation and deregulation mechanisms reflected here. Bcl-2, for instance, is supposed to dissociate cell survival from proliferation [40].

The resistance to apoptosis gradually increases for tubular and tubulovillous adenomas and is affected by their origin: the carcinoma-free or the carcinoma-bearing bowel. The reduction of apoptotic cells is followed by an increase in cycling cells. The steps investigated here will now be discussed.

\subsection{Follow-up group}

Colorectal mucosa in FAP patients is characterised by hyperproliferation [10,41]. In patients without cancer history, a balance exists between proliferation and aptoptosis. The percentages of cycling cells, the proliferative compartment and the amount of apoptotic cells are nearly identical. This leads to the assumption that cycling cells quickly pass through the G1 phase. This also suggests a high proliferative activity. Positive relations between the apoptotic fraction and S and G2M phase fractions indicate a connection between apoptosis and proliferation in mucosa. The reverse correlation between the apoptotic fraction and Ki67 positive cells, and low Ki67 values per se may be related to the fact that rapid apoptosis prevents cells from the G1 arrest [14] whereas delayed apoptosis $[15,21,23]$ promotes G1 arrest [14,27]. Lacking relations between Ki67 positive cells and S and G2M phase fractions in mucosa lend support to this suggestion. It is worth noting that already patients with a cancer history show a slight imbalance. Different proliferative conditions in mucosa depending on a carcinoma history resemble increased labeling indices seen in mucosa from FAP patients independent of the time elapsed after surgery [36].

In adenomas, proliferative and apoptotic conditions do not depend upon a carcinoma or carcinomafree history of the FAP patient, but on their histological type. In tubular adenomas, the apoptotic 
fraction is in balance with the proliferative compartment. A relation between apoptotic and mitotic activities was described for tubular adenomas [1]. The absence of a correlation between proliferation and apoptosis in this study has not been fully understood especially since this relation is evident in tubulovillous adenomas where apoptosis is further reduced. The increase in Ki67 positive cells in tubular and tubulovillous adenomas also seen by Dippe [11] suggests a longer G1 phase leading to long-lived cells in both types of adenomas. This was also discussed for sporadic adenomas [19]. For sporadic tubulovillous adenomas in cell culture, Bedi [3] observed a more prolonged inhibition of apoptosis compared with sporadic tubular adenomas. For villous adenomas, a significantly lower apoptotic index was described without an equivalent decrease in mitotic activity [1]. Stepwise reduced apoptosis may be related to the known increasing risk for malignisation from tubular to villous adenomas [28].

\subsection{Surgically treated group}

Although the need for surgical treatment is based only on clinical signs, the resistance to apoptosis in tubular adenomas increased significantly. Ki67 positive cells, however, remain on the same level as in the follow-up group. No relation between apoptosis and proliferation is evident.

In tubular adenomas from the carcinoma-bearing bowel, the significant increase in Ki67 positive cells is connected with a positive relation to $S$ phase cells, here observed for the first time. In addition, a positive correlation exists between S phase, G2M phase and resistant cells. These facts together with the high frequency of the adenoma subtype characterised by enhanced proliferative capacity suggest an increased proliferative activity. This may be due to an expanded growth fraction compared to the carcinoma-free bowel. A correlation between proliferation and apoptosis was not detected. In situ investigations in familial adenomatous polyposis illustrating an increase in apoptosis and in cycling cells consider this as an abnormally high turnover rate [38].

In tubulovillous adenomas from the carcinoma-bearing bowel, susceptibility to apoptosis continues to decrease. At the same time, the Ki67 score remains high and S and G2M phase fractions decrease. The latter may be due to shorter cell cycle times, especially as the chromatin in situ test indicates a high proliferative capacity.

The reverse correlation between Ki67 positive cells and apoptosis, observed in mucosal cells, has now turned into a positive correlation $(p<0.07)$. The latter was described for adenomas with sporadic p53 immunostaining which is considered as a transient expression of the wild type p53 protein [23] and for colorectal carcinomas [2].

In summary, tubular and tubulovillous adenomas from both the carcinoma-free and carcinomabearing bowel differ from each other in the degree of resistance to apoptosis, and not in the Ki67 values. In the carcinoma-free bowel, enhanced Ki67 values seem to reflect G1 cells with a long phase duration, which accounts for long-lived cells. In the carcinoma-bearing bowel, however, an extended growth fraction together with a higher proliferative capacity seems to be a rather decisive factor.

The gradual increase in resistance to apoptosis followed by an increase in cycling cells should encourage the treatment of FAP patients with drugs such as sulindac [42] inducing apoptosis [3] paralleled by reducing Ki67 positive cells [45].

Further cell kinetic investigations involving immunohistochemical analysis of gene products are needed to provide a cut-off level for apoptotic cells in relation to Ki67 positive cells. This would help to identify FAP patients who are at a higher risk and have a greater need for surgical treatment, and would complement clinical methods for determining the time for surgical intervention. 


\section{Acknowledgements}

This work was supported by Deutsche Krebshilfe, Dr Mildred Scheel Stiftung für Krebsforschung (M33/92/We2).

\section{References}

[1] T. Arai and I. Kino, Role of apoptosis in modulation of the growth of human colorectal tubular and villous adenomas, J. Pathol. 176 (1995), 37-44.

[2] G.B. Baretton, J. Diebold, G. Christoforis, M. Vogt, C. Müller, K. Dopfer, K. Schneiderbonger, M. Schmidt and U. Lohrs, Apoptosis and immunhistochemical bcl-2 expression in colorectal adenomas and carcinomas-aspects of carcinogenesis and prognostic significance, Cancer 77 (1996), 255-264.

[3] A. Bedi, P.J. Pasricha, A.J. Akhtar, J.B. Barber, G.C. Bedi, F.M. Giardiello, B.A. Zehnbauer, St.R. Hamilton and R.J. Jones, Inhibition of apoptosis during development of colorectal cancer, Cancer Res. 55 (1995), 1811-1816.

[4] P. Bedossa, T. Poynard, J. Bacci, S. Naveau, G. Lemaigre, J.C. Chaput and E. Martin, Expression of histocompatibility antigens and characterization of the lymphocyte infiltrate in hyperplastic polyps in the large bowel, Hum. Pathol. 21 (1990), 319-324.

[5] W.F. Bodmer, C.J. Bailey, J. Bodmer, H.J.R. Bussey, A. Ellis, P. Gorman, F.C. Lucibello, V.A. Murday, S.H. Rider, P. Scambler, D. Sheer, E. Solomon and N.K. Spurr, Localisation of the gene for familial adenomatous polyposis on chromosome 5, Nature 328 (1987), 614-616.

[6] S. Bosari, L. Moneghini, D. Graziani, A. Lee, J.J. Murray, G. Coggi and G. Viale, Bcl-2 oncoprotein in colorectal hyperplastic polyps, adenomas, and adenocarcinomas, Hum. Pathol. 26 (1995), 534-540.

[7] H.I.R. Bussey, Familial Polyposis Coli: Family Studies, Histopathology, Differential Diagnosis, and Results of Treatment, Johns Hopkins University Press, Baltimore, 1975.

[8] J.L. Cordell, B. Falini, W.N. Erber, A.K. Ghosh, Z. Abdulaziz, St. Macdonald, K.A.F. Palford, H. Stein and D.Y. Mason, Immunoenzymatic labeling of monoclonal antibodies using immune complexes of alkaline phosphatase and monoclonal anti-alkaline phosphatase (APAAP complexes), J. Histochem. Cytochem. 32 (1984), 219-229.

[9] Z. Darzynkiewicz, S. Bruno, G. Del Bino, W. Gorczyca, M.A. Hotz, P. Lassota and F. Traganos, Features of apoptotic cells measured by flow cytometry, Cytometry 13 (1992), 795-808.

[10] E.E. Deschner and M. Lipkin, Proliferative patterns in colonic mucosa in familial polyposis, Cancer 35 (1975), 413-418.

[11] B. Dippe, H. Petrowsky, S. Krüger, K.V. Jentzkowski, M. Schneider and M. Lorenz, Malignitätspotential kolorektaler Polypen-histomorphometrische, histochemische und immunhistochemische Untersuchung zur Dysplasie-KarzinomSequenz, Zentralbl. Chir. 120 (1995), 556-563.

[12] M.D. Erisman, J.K. Scott and S.M. Astrin, Evidence that the familial adenomatous polyposis gene is involved in a subset of colon cancers with a complementable defect in C-myc regulation, Proc. Natl. Acad. Sci. USA 86 (1989), 4264-4268.

[13] J. Gerdes, H. Lemke, H. Baisch, H.-H. Wacker, U. Schwab and H. Stein, Cell cycle analysis of a cell proliferationassociated human nuclear antigen defined by the monoclonal antibody Ki67, J. Immunol. 133 (1984), 1710-1715.

[14] Ch. Guillouf, X. Grana, M. Selvakumaran, A. De Luca, A. Giordano, B. Hoffmann and D.A. Liebermann, Dissection of the Genetic Programs of p53-induced apoptosis unmasks G1 arrest, Blood 85 (1995), 2691-2698.

[15] E.A. Harrington, A. Fanidi and G.I. Evan, Oncogenes and cell death, Curr. Opin. Genet. Dev. 4 (1994), 120-129.

[16] W. Hiddemann, J. Schumann, M. Andreeff et al., Convention nomenclature for DNA cytometry, Cytometry 5 (1984), $445-446$.

[17] D.M. Hockenbery, M. Zutter, W. Hickey, M. Nahen and S.J. Korsmeyer, BC 12 protein is topographically restricted in tissues characterized by apoptotic cell death, Proc. Natl. Acad. Sci. USA 88 (1991), 6961-6965.

[18] M.A. Hotz, J. Gong, F. Traganos and Z. Darzynkiewicz, Flow cytometric detection of apoptosis: Comparison of the assays of in situ DNA degradation and chromatin changes, Cytometry 15 (1994), 237-244.

[19] P.G. Johnston, J. O'Brien, P.A. Dervan and D.N. Carney, Immunohistochemical analysis of cell kinetic parameters in colonic adenocarcinomas, adenomas, and normal mucosa, Hum. Pathol. 20 (1989), 696-700.

[20] S.A. Khan, N. Azam, R. Sanghvi, S. Mundle, C. Jones, S. Shott and A. Raza, Patterns of cell proliferation and programmed cell death in carcinoma of the breast, Cell Prolif. 27 (1994), 410.

[21] R. Kikuchi-Yanoshita, M. Konishi, S. Ito, M. Seki, K. Tanaka, Y. Maeda, H. Iina, M. Fukayama, M. Koike, T. Mori, H. Sakuraba, H. Fukunari, T. Iwama and M. Miyaki, Genetic changes of both p53 alleles associated with the conversion from colorectal adenoma to early carcinoma in familial adenomatous polyposis and non-familial adenomatous polyposis patients, Cancer Res. 52 (1992), 3965-3971. 
[22] K.W. Kinzler, M.C. Nilbert, Su Li-Kuo, B. Vogelstein, T.M. Bryan, D.B. Levy, K.J. Smith, A.C. Preisinger, P. Hedge, D. McKechnie, R. Finniear, A. Markham, J. Groffen, M.S. Boguski, S.F. Altschul, A. Horii, H. Ando, Y. Miyoshi, Y. MiKi, I. Nishisho and Y. Nakamura, Identification of FAC locus genes from chromosome 5q21, Science 253 (1991), 661-664.

[23] M. Kobayashi, H. Watanabe, Y. Ajioka, M. Yoshida, J. Hitomi and H. Asakura, Correlation of p53 protein expression with apoptotic incidence in colorectal neoplasia, Virchows Arch. 427 (1995), 27-32.

[24] J.E. Kunicka, Z. Darzynkiewicz and M.R. Melamed, DNA in situ sensitivity to denaturation: A new parameter for flow cytometry of normal human colonic epithelium and colon carcinoma, Cancer Res. 47 (1987), 3942-3947.

[25] P. Maier and H.P. Schawalder, A two-parameter flow cytometry protocol for detection und characterisation of the clastogenic, cytostatic and cytotoxic activities of chemicals, Mutat. Res. 164 (1986), 369-379.

[26] T.J. McDonnell, M.M.C. Hsu, S.M. Brisbay, K. McConnell, S.M. Tu and M.L. Campbell and J. Rodriguez-Villanueva, The bcl-2 oncogene: Apoptosis and neoplasia, Radiat. Res. 136 (1993), 307-312.

[27] M. Miyaki, M. Okamoto, A. Yamanaka, Y. Maeda, K. Tanaka, R. Kikuchi, T. Iwama, T. Ikeuchi, A. Tonomura, Y. Nakamura, R. White, Y. Miki, J. Utsunomiya and M. Koike, Genetic changes and histopathological types in colorectal tumors from patients with familial adenomatous Polyposis, Cancer Res. 50 (1990), 7133-7166.

[28] B.C. Morson, The Polyp-cancer sequence in the large bowel, Proc. R. Soc. Med. 67 (1974), 451-457.

[29] B.C. Morson and L.H. Sobin, Histological typing of intestinal tumours. International histological classification of tumours, WHO, Geneva, 1976 (No. 15).

[30] I. Nishisho, Y. Nakamura, Y. Miyoshi, Y. Miki, H. Ando, A. Horii, K. Koyama, J. Utsunomiya, S. Baba, P. Hedge, A. Markham, A.J. Krush, G. Petersen, S.R. Hamilton, M.C. Nilbert, D.B. Levy, T.M. Bryan, B.A. Preisinger, K.J. Smith, Su Li-Kuo, K.W. Kinzler and B. Vogelstein, Mutations of chromosome 5q21 genes in FAP and colorectal cancer patients, Science 253 (1991), 665-669.

[31] P.J. Pasricha, A. Bedi, K. O'Cannor, A. Rashid, A.J. Akhtar, M.L. Zahurak, S. Piantadosi, S.R. Hamiltton and F.M. Giardiello, The effects of sulindac on colorectal proliferation and apoptosis in familial adenomatous polyposis, Gastroenterology 109 (1995), 994-998.

[32] P.S. Rabinovitch, Phoenix Flow Systems, San Diego, CA 92121.

[33] M. Schena, L.G. Larsson, D. Gottardi, G. Gaidano, M. Carlsson, K. Nilsson and F. Caligaris-Cappio, Gowth and differentiation assosiated expression of bcl-2 in b-chronic lymphocytic leukemia cells, Blood 79 (1992), 2981-2989.

[34] S.J. Shiff, L. Qiao, L.L. Tsai and B. Rigas, Sulindac Sulfide and aspirin-like compound, inhibits proliferation, causes cell cycle quiescence and induces apoptosis in HT-29 colon adenocarcinoma cells, J. Clin. Invest. 96 (1995), 503.

[35] K.D. Steck, T.J. McDonnell and A.K. El-Naggar, Flow cytometric analysis of apoptosis and bcl-2 in human solid neoplasms, Cytometry 20 (1995), 154-161.

[36] L. Steenbeck and K.H. Jacobasch, Zellproliferation der Darmschleimhaut bei Patienten mit familiärer Adenomatosis coli, J. Gastroenterol. 49 (1989), 29-31.

[37] M. Stöhr, M. Vogt-Schaden, M. Knobloch, R. Vogel and G. Futtermann, Evaluation of eight fluorochrome combinations for simultanus DNA/protein flow analysis, Stain Technol. 53 (1978), 205-215.

[38] J. Sträter, K. Koretz, A.R. Günthert and P. Möller, In situ detection of enterocytic apoptosis in normal colonic mucosa and in familial adenomatous polyposis, Gut 37 (1995), 819-825.

[39] B. Streller, Mathematische Auswertung von DNA-Verteilungskurven, in: Symposium Automatisierte Informationsverarbeitung im Krankenhaus, Institut für Medizinische Informatik und Biometrie, Humboldt Universität, Berlin, 1984, p. 73.

[40] L.D. Vaux, S. Cory and J.M. Adams, Bcl-2 gene promotes haemopoietic cell survical and cooperates with c-myc to immortalize pre-B cells, Nature 335 (1988), 440-442.

[41] B. Vogelstein, E.R. Fearon, St. Hamiltton, S.E. Kern, A.C. Preisinger, M. Leppert, Y. Nakamura, R. White, A.M.M. Smits and J.L. Bos, Genetic alterations during colorectal tumor development, J. Med. 319 (1988), $25-32$.

[42] W.R. Waddel and R.W. Longhry, Sulindac for polyposis of the colon, J. Surg. Oncol. 24 (1983), 83-87.

[43] H. Weiß, M. Görlich, J. Frege, A. Granetzny, B. Streller, U. Nitschke and U. Weiher, Cytokinetic investigations in human breast cancer by flow cytometrically recorded DNA/protein distributions, Anal. Cell Pathol. 10 (1996), 59-72.

[44] H. Weiß, P. Langen, U. Nitschke and I. Thun, Flow cytometrically monitored chromatin in situ testing in the breast cell line H184A1N4, Cancer Res. Clin. Oncol. 120 (1994), 399-402.

[45] G. Winde, K.W. Schmid, W. Schlegel, R. Fischer, H. Osswald and H. Bünte, Complete reversion and prevention of rectal adenomas in colectomized patients with familial adenomatous polyposis by rectal low-dose Sulindac maintenance treatment, Dis. Colon Rectum 38 (1995), 813-830.

[46] A.H. Wyllie, Apoptosis and the regulation of cell numbers in normal and neoplastic tissues, an overview, Cancer Metastasis Rev. 11 (1992), 95-103.

[47] J. Zante, J. Schumann, B. Barlogie, W. Göhde and T. Büchner, New preparating and staining procedures for specific and rapid analysis of DNA distribution, in: Pulse Cytophotometry. II, W. Göhde, J. Schumann and T. Büchner, eds, European Press, Ghent, pp. 97-106. 


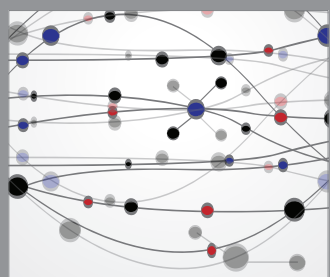

The Scientific World Journal
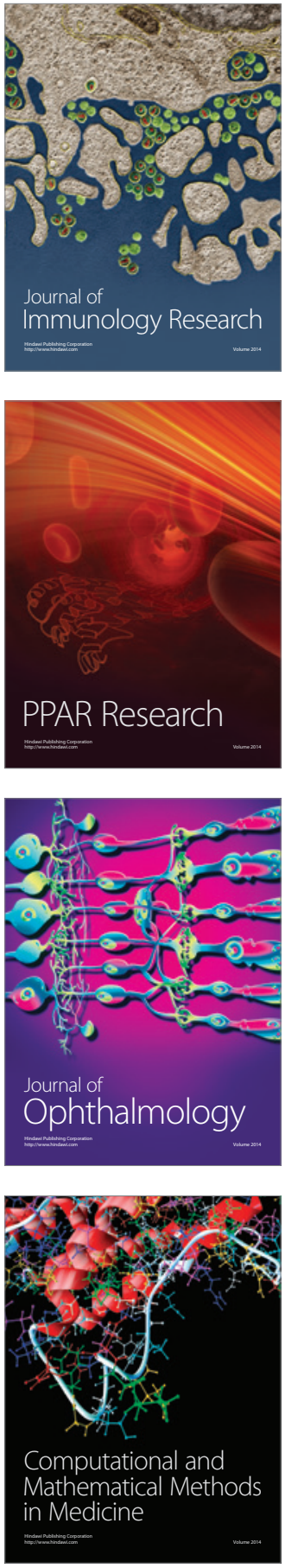

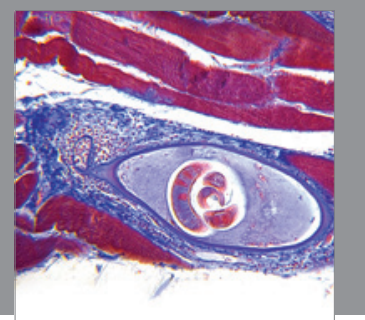

Gastroenterology

Research and Practice
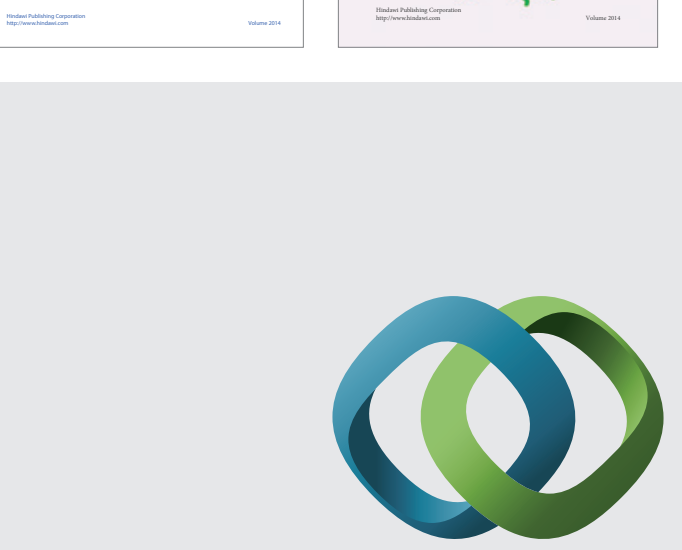

\section{Hindawi}

Submit your manuscripts at

http://www.hindawi.com
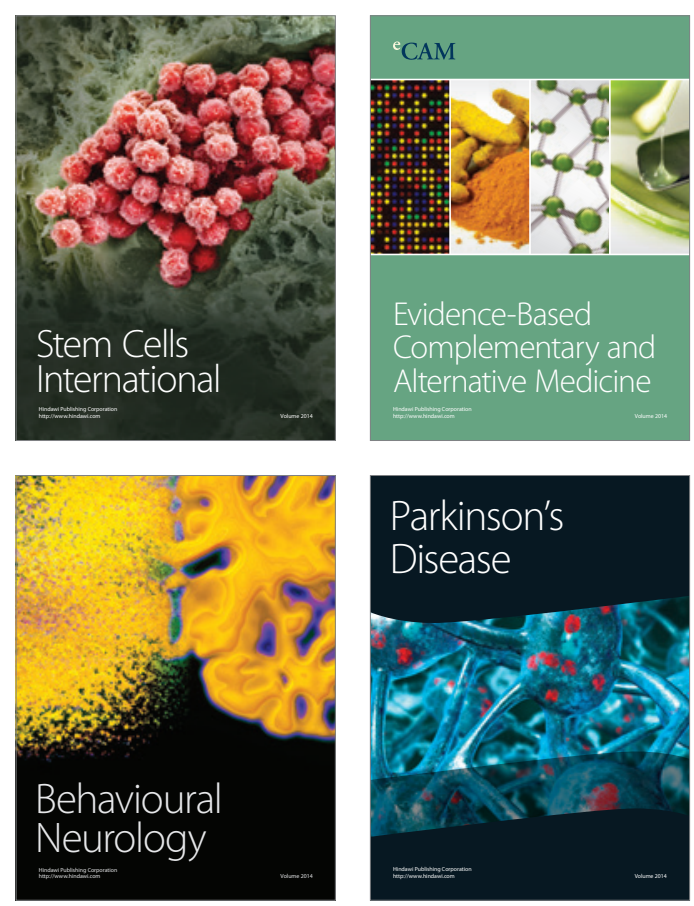

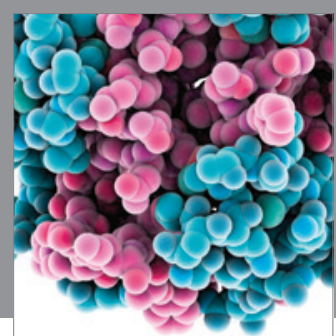

Journal of
Diabetes Research

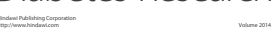

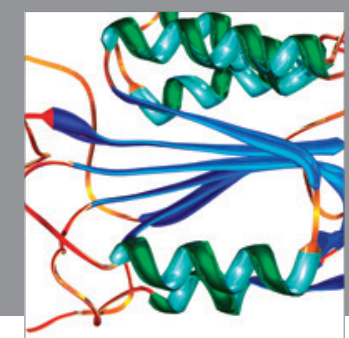

Disease Markers
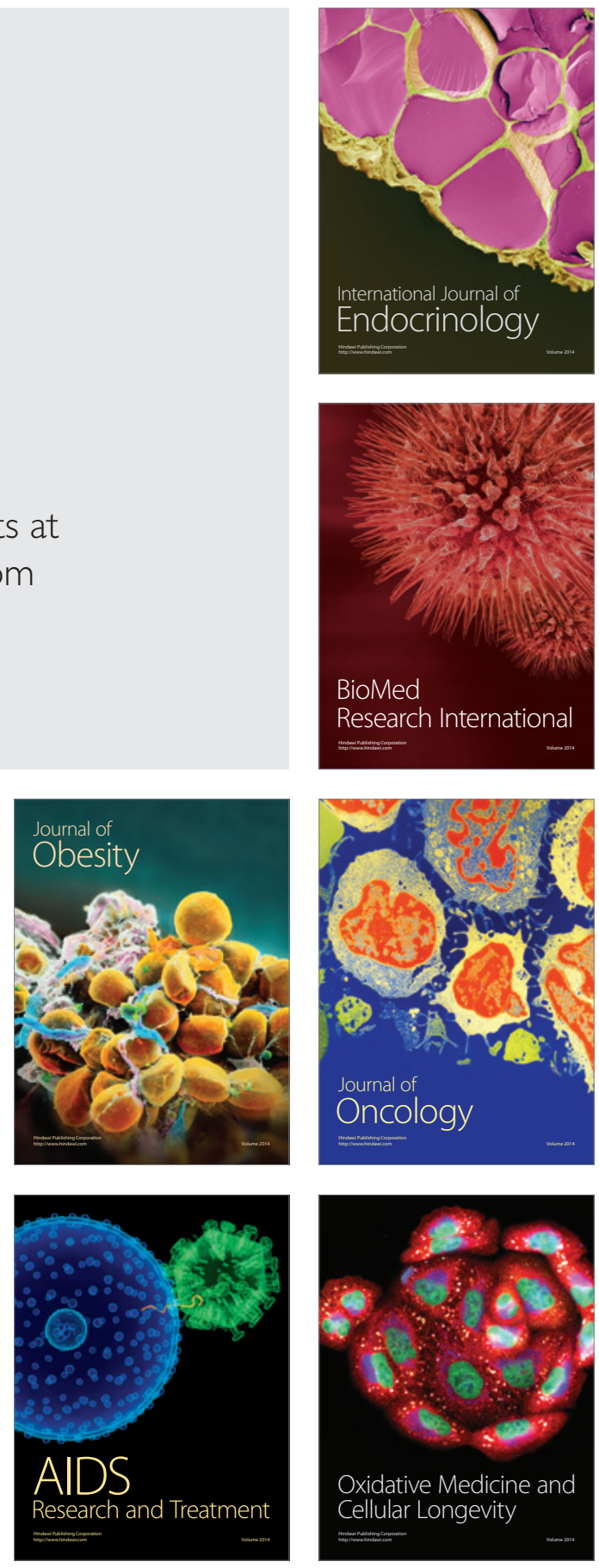